\title{
A Study to Formulate a Strategy to Prevent Ventriculoperitoneal Shunt Infection
}

\author{
$\begin{array}{llll}\text { T. P. Jeyaselvasenthilkumar } & \text { V. G. Ramesh } & \text { C. Sekar } & \text { S. Sundaram }\end{array}$ \\ ${ }^{1}$ Department of Neurosurgery, Institute of Neurology, Madras \\ Medical College, Chennai, Tamil Nadu, India \\ Address for correspondence T. P. Jeyaselvasenthilkumar, MCh \\ (neuro), F4, Olympia Block, RC Westminster, 46, Kamaraj Road, \\ Indian J Neurosurg 2015;4:74-79. \\ Kodungaiyur, Chennai 118, Tamil Nadu, India \\ (e-mail: drjselva@gmail.com).
}

\begin{abstract}
Keywords

- shunt infection

- hydrocephalus

- cerebrospinal fluid

Aim This study aims to formulate a least expensive yet effective and simple surgical strategy for prevention of ventriculoperitoneal shunt infections.

Patients and Methods This study was done prospectively in 486 cases admitted during the period from 2006 to 2013. Patients were divided into two groups and a protocol was devised to reduce shunt infections. In group 1, the shunt was done following the protocol and the other group, protocol was not followed. The various factors contributing to shunt infection were analyzed in detail and its statistical significance worked out.

Results The group 1 where protocol is followed showed $0 \%$ incidence of shunt infection. In the group, where the protocol was not followed, it is observed that prolonged surgery, use of intermediate skin incision, and previous shunt surgery contribute to increased risk of shunt infection.
\end{abstract}

\section{Introduction}

Hydrocephalus is an accumulation of excess cerebrospinal fluid (CSF) in the ventricular system of brain because of an increased secretion, defective absorption, or disturbances in CSF circulation. The most significant contribution to the treatment of hydrocephalus was made by Nulsen and Spitz, ${ }^{1}$ who in 1952, first performed the valve-regulated shunt system to prevent the reflux of venous blood. In 1908, Cushing $^{2}$ first performed the ventriculoperitoneal (VP) shunt, but that did not gained popularity until after the publications of the work by Scarff ${ }^{3}$ in 1963. VP shunt placement is a relatively common neurosurgical procedure performed for the treatment of hydrocephalus. One of the principal complications associated with the use of these devices is infection, with infection rates ranging from 1.5 to $38 \%$. Age seems to be an important risk factor, with neonates and young children frequently affected. Shunt infection leads to severe morbidity for the patient. Of even greater concern is the infection-related mortality, with rates up to $20 \%$ reported in the literature.

received

October 2, 2014

accepted

May 25, 2015

published online

July 28, 2015
DOI http://dx.doi.org/

$10.1055 / \mathrm{s}-0035-1558960$.

ISSN 2277-954X.
Although several authors have adopted several protocol and reduced the incidence of shunt infection. Considering the morbidity, mortality, and the financial burden in treating shunt infections, there is a need to evolve a strategy to prevent shunt infection completely and to bring the incidence to $0 \%$.

\section{Aim of the Study}

The aim of this study is to formulate a least expensive yet effective and simple surgical strategy for prevention of VP shunt infections.

\section{Patients and Methods}

This study was done prospectively in 486 cases admitted during the period from 2006 to 2013.

\section{Inclusion Criteria}

All patients with congenital hydrocephalus, tumorassociated hydrocephalus, hydrocephalus associated with

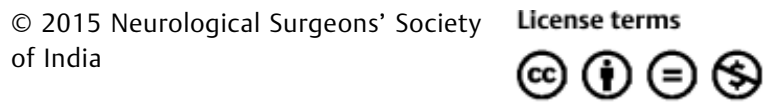


spinal dysraphism, normal pressure hydrocephalus, postmeningitic hydrocephalus without active meningitis were included.

\section{Exclusion Criteria}

Immunocompromised patients with hydrocephalus, hydrocephalus associated with active meningitis, patients having skin diseases, patients with focal sepsis.

The patients were divided into the following two groups:

Group 1: VP shunt was done based on protocol to reduce shunt infection.

Group 2: No protocol was followed while doing the shunt. Group 1 patient's VP shunt was done based on the protocol. The details of the protocol modified from the one suggested by Choux et $\mathrm{al}^{4}$ are as follows:

1. It is done as a first case in the operative list.

2 . It is done by an experienced surgeon.

3. Surgeon, anesthetist and staff nurse alone in the operating room.

4. Skin must be thoroughly prepared and draped, and should not be touched during the surgical procedure.

5. Avoiding autoclaved gloves.

6. Shunt tube pack must be opened just before its insertion.

7. Shunt tube should not be immersed in saline for checking the valve.

8. Minimizing the duration of surgery.

9. Perioperative antibiotics given for all cases.

10. Avoiding intermediate skin incisions along shunt tube tract.

11. Patient advised not to lie over the operated side to avoid pressure over the shunt pump.

\section{Follow-Up}

All these patients were followed up by phone interviews and out-patient reviews for signs and symptoms of shunt infection.

\section{Diagnosis of Shunt Infection}

1. Redness and tenderness along shunt tube tract.

2. Wound gaping and pus discharge of either the cranial or abdominal wound.
3. Exposed shunt tube anywhere along the tract.

4. Signs of meningeal irritation.

5. Unexplained fever.

\section{Treatment of Infection}

The treatment options for shunt infection are as follows:

1. Conservative.

2. Shunt tube removal, treatment of infection, fresh VP shunt, if shunt dependent.

The removed shunt tube was subjected to culture and sensitivity. CSF sample was also taken for biochemical analysis, culture, and sensitivity and cytology. Blood culture, urine culture, widal test, peripheral smear for malarial parasite, chest X-ray was done to rule out other causes for fever. Conservative treatment includes treatment with antibiotics covering gram positive, gram negative, and anaerobes such as crystalline penicillin, gentamicin, and metronidazole.

\section{Results}

In group 1, comprising 80 cases, for whom the shunt was done based on the protocol, none of the cases were infected.

In group 2, comprising 406 cases, where the protocol was not followed while doing the shunt, 22 cases got infected between 13 days and 1year. The details about various steps in the protocol and their contribution to the incidence of shunt infection are shown in -Table 1.

In the group II comprising 406 cases, where the protocol was not followed while doing the shunt, 226 were males and 180 were females. Overall, 270 cases were not operated as a first case in the operating list, the shunt tube was immersed in saline in 368 cases for checking the valve, the shunt was done as an emergency procedure in 176 patients, history of shunt was present in 14 of the patients, pre-op antibiotics was not used in 393 patients, intermediate skin incisions were used in 7 patients, and the duration of surgery lasted for more than an hour in 5 patients.

In a group of 270 patients where shunt was not done as a first case, 14 patients got infected (5.1\%). Of the 368 patients, whose shunt tube was immersed in saline, 15 patients got infected (4.07\%). Of the 176 patients operated as emergency,

Table 1 Factors contributing to the incidence of shunt infection

\begin{tabular}{|l|l|l|l|}
\hline Parameter & Total cases & Infected & Percentage \\
\hline Not as first case & 270 & 14 & 5.18 \\
\hline Emergency & 176 & 4 & 2.27 \\
\hline Immersion in saline & 368 & 15 & 4.07 \\
\hline History of previous shunt & 14 & 2 & 14.28 \\
\hline No pre-op antibiotics & 393 & 22 & 5.59 \\
\hline Intermediate skin incision & 7 & 1 & 14.28 \\
\hline Duration of surgery $>1 \mathrm{~h}$ & 5 & 1 & 20 \\
\hline
\end{tabular}




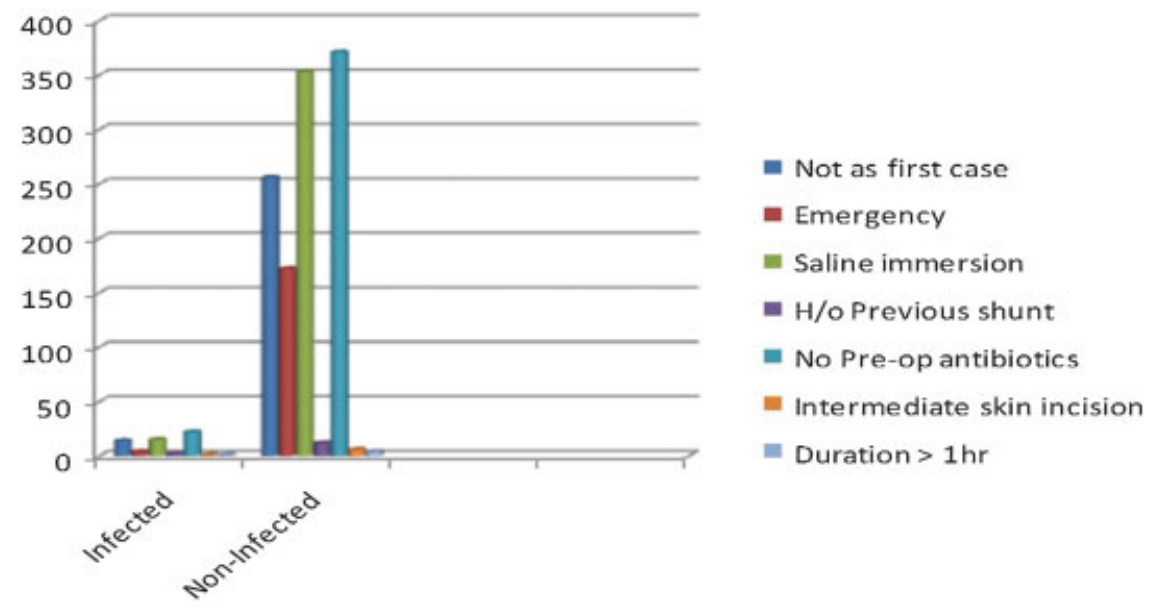

Fig. 1 Various parameters in infected versus noninfected.

4 patients got infected (2.2\%). With 14 patients already having a shunt done, 2 patients got infected (14.2\%). Of the 393 patients for whom pre-op antibiotics were not used, 22 patients got infected (5.5\%). Of the seven patients, one patient for whom intermediate skin incisions were used got infected (14.28\%). Of the five patients where the shunt procedure was lasted for more than 1 hour, one patient got infected (20\%) (-Fig. 1).

Of the 22 cases which got infected, $36.36 \%$ (eight cases) got infected in first 2 months following surgery. Of the 91 infants, for whom shunt was done, eight patients got infected (8.79\%). Of the 18 neonates for whom shunt was done, none of them got infected. Overall, 6.19\% of male shunts and $4.44 \%$ of female shunts got infected (-Fig. 2).

Majority of the shunt infections were seen in aqueductal stenosis, followed by tumor-associated hydrocephalus. Posthemorrhagic and postinfective hydrocephalus comes next in the list. Two cases of myelomeningocele-associated hydrocephalus got infected.

Of all the infected cases, three patients were managed conservatively with antibiotics, three patients were managed with shunt removal only as they were shunt independent, the remaining 16 patients were managed with fresh shunt after removing the infected shunt and controlling the infection.

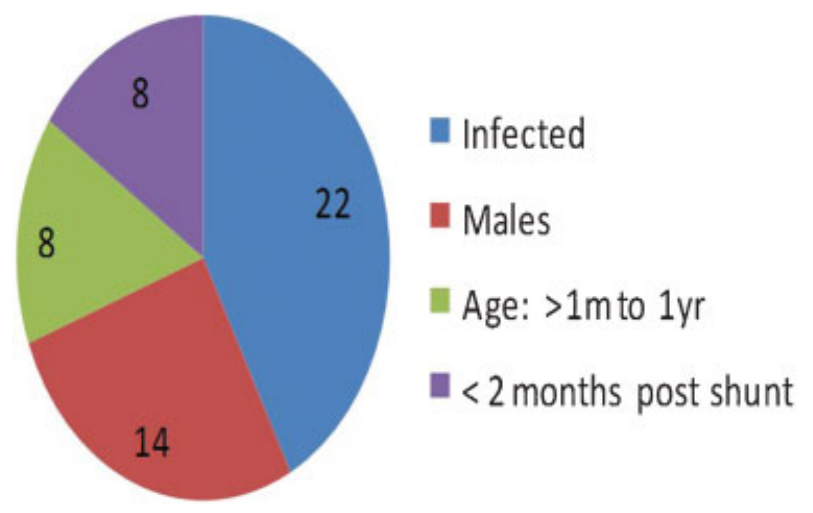

Fig. 2 Demographic profile of infected cases.
On subjecting the removed shunt tube for culture, Staphylococcus aureus, Staphylococcus epidermidis, and Escherichia coli was grown in three cases, respectively. Rest of the cultures were negative.

The antibiotics used to treat shunt infection were crystalline penicillin, gentamicin, and metronidazole. In some patients, cefoperazone sulbactum and piperacillin were also used based on culture and sensitive reports.

In a group of 80 patients, for whom shunt was done based on the protocol none of the cases got infected (-Fig. $\mathbf{3}$ ).

\section{Stastical Analysis}

Stastical analysis was done with independent sample test and chi-square test (-Tables 2-4).

For shunts which have not been done as a first case, there is a statistically significant difference between controls and patients groups $(p=0.000)<(p=0.05)$.

For the patients where the shunt system was immersed in saline, there is statistically significant difference between controls and patients groups $(p=0.000)<(p=0.05)$.

For shunts done as an emergency procedure, there is statistically significant difference between controls and patients groups $(p=0.000)<(p=0.05)$.

For patients who already underwent shunt surgery, there is no statistically significant difference between controls and patients groups. $(p=0.341)>(p=0.005)$.

For the use of perioperative antibiotics, there is statistically significant difference between controls and patients groups $(p=0.000)<(p=0.05)$.

For patients where an intermediate skin incision was used, there is no statistically significant difference between controls and patients groups $(p=0.238)>(p=0.05)$.

For patients where the duration of surgery lasted for more than an hour, there is no statistically significant difference between controls and patients groups $(p=0.319)>(p=0.05)$.

\section{Discussion}

Thus, from the earlier study, it has become clear that by following meticulous surgical technique, the shunt infection 


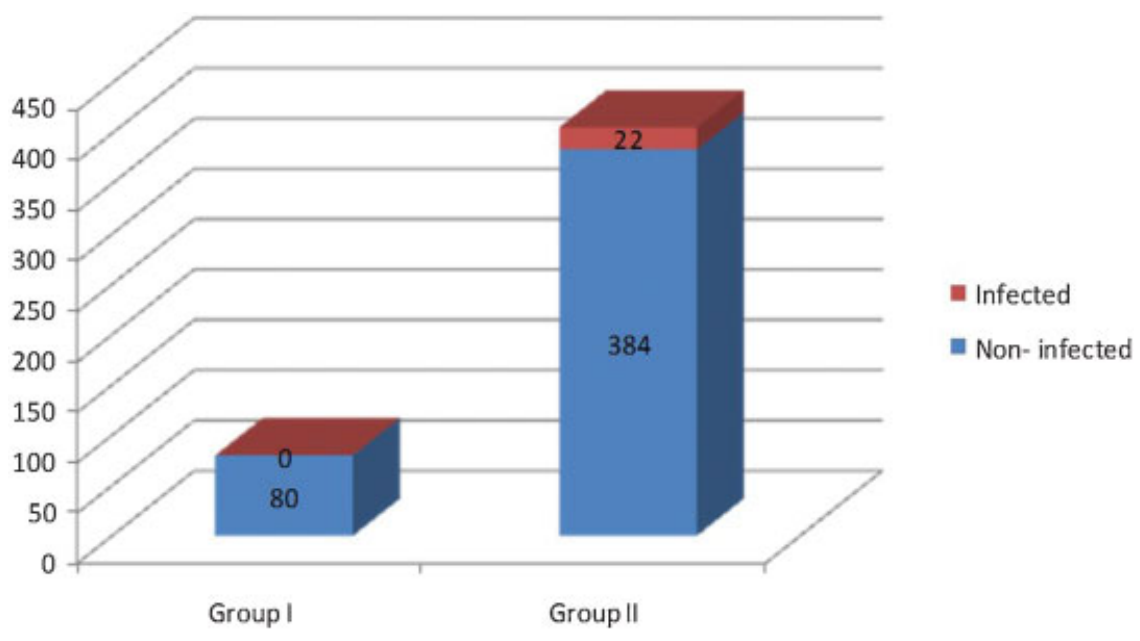

Fig. 3 Infected versus noninfected in group I and group II.

Table 2 Independent sample test

\begin{tabular}{|c|c|c|c|c|c|}
\hline & \multicolumn{5}{|c|}{$t$-test for equality of means } \\
\hline & \multirow[t]{2}{*}{$t$} & \multirow[t]{2}{*}{$\mathrm{d} f$} & \multirow[t]{2}{*}{ Sig. (two-tailed) } & \multicolumn{2}{|c|}{$\begin{array}{l}\text { 95\% Confidence interval of the } \\
\text { difference }\end{array}$} \\
\hline & & & & Lower & Upper \\
\hline \multicolumn{6}{|l|}{ Not as first case } \\
\hline Equal variances assumed & -12.860 & 484.000 & 0.000 & -0.778 & -0.572 \\
\hline Equal variances not assumed & -28.995 & 405.000 & 0.000 & -0.721 & -0.629 \\
\hline \multicolumn{6}{|l|}{ Immersed in saline } \\
\hline Equal variances assumed & 25.602 & 484.000 & 0.000 & 0.823 & 0.960 \\
\hline Equal variances not assumed & 57.724 & 405.000 & 0.000 & 0.861 & 0.922 \\
\hline \multicolumn{6}{|l|}{ Emergency } \\
\hline Equal variances assumed & 6.728 & 484.000 & 0.000 & 0.271 & 0.495 \\
\hline Equal variances not assumed & 10.426 & 231.807 & 0.000 & 0.311 & 0.456 \\
\hline \multicolumn{6}{|l|}{$\mathrm{H} / 0$ Previous shunt } \\
\hline Equal variances assumed & 953 & 484.000 & 0.341 & -0.026 & 0.074 \\
\hline Equal variances not assumed & 1.178 & 145.332 & 0.241 & -0.016 & 0.065 \\
\hline \multicolumn{6}{|l|}{ Antibiotic } \\
\hline Equal variances Assumed & 49.077 & 484.000 & 0.000 & -1.007 & -0.929 \\
\hline Equal variances not assumed & -110.650 & 405.000 & 0.000 & -0.985 & -0.951 \\
\hline \multicolumn{6}{|l|}{ Intermediate incision } \\
\hline Equal variances assumed & 1.182 & 484.000 & 0.238 & -0.011 & 0.046 \\
\hline Equal variances not assumed & 2.666 & 405.000 & 0.008 & 0.005 & 0.030 \\
\hline \multicolumn{6}{|l|}{ Duration of surgery } \\
\hline Equal variances assumed & 997 & 484.000 & 0.319 & -0.012 & 0.037 \\
\hline Equal variances not assumed & 2.247 & 405.000 & 0.025 & 0.002 & 0.023 \\
\hline \multicolumn{6}{|l|}{ Infected } \\
\hline Equal variances assumed & -2.136 & 484.000 & 0.033 & -0.104 & -0.004 \\
\hline Equal variances not assumed & 4,817 & 405.000 & 0.000 & -0.076 & -0.032 \\
\hline
\end{tabular}


78 Shunt Infection Jeyaselvasenthilkumar et al.

Table 3 Age type cross-tabulation

\begin{tabular}{|c|c|c|c|}
\hline \multicolumn{4}{|c|}{ Age type cross-tabulation } \\
\hline \multicolumn{4}{|l|}{ Count } \\
\hline & \multicolumn{3}{|l|}{ Type } \\
\hline & Group II & Group I & Total \\
\hline \multicolumn{4}{|l|}{ Age } \\
\hline$\leq 12$ & 211 & 37 & 248 \\
\hline$>12$ & 195 & 43 & 238 \\
\hline Total & 406 & 80 & 486 \\
\hline
\end{tabular}

rate has been reduced to $0 \%$. The majority of shunt infections are observed within 2 months of its insertion and are a result of probable direct contamination at the time of its insertion. In accordance with data in other reports in which the infection rate ranged from 3.8 to $27 \%$, the infection rate was $5.4 \%$ in our Institute. After introduction of this new strategy, the infection rate was reduced from 5.4 to $0 \%$. In agreement with other studies, more than one-third of the infections occurred in children younger than 1 year of age and on the contrary none of the neonates got infected. For patients undergoing multiple shunts, the infection rate increased from 5.4 to $14.28 \%$. This is supported by other studies by George et $\mathrm{al}^{5}$ and Meirovitch et al. ${ }^{6}$ In accord with the report of George et al, the experience of the surgeon is the most important factor in the reduction of shunt infection rates, we also believe that shunt procedure should be performed only by an experienced surgeon. In various literatures, 70 to $75 \%$ of shunt infections were caused by $S$. epidermidis and 20 to $25 \%$ of infections were because of $S$. aureus, but in our study, most of the cultures were negative. Regarding the use of prophylactic antibiotics, there is zero infection in the group where perioperative antibiotics were used. On the contrary, 5.4\% infection occurred in the group where no perioperative antibiotics were used. Haines and Taylor, ${ }^{7}$ despite demonstrating the reduction in infection with the use of prophylactic antibiotics, were unable to show a statistically significant reduction. We routinely use the prophylactic antibiotic at the time of induction. On the
Table 5 Comparison of various studies on shunt infection

\begin{tabular}{|c|c|c|c|}
\hline Authors & $\begin{array}{l}\text { Year of } \\
\text { study }\end{array}$ & $\begin{array}{l}\text { No. of } \\
\text { cases }\end{array}$ & $\begin{array}{l}\text { Infection } \\
\text { rate (\%) }\end{array}$ \\
\hline George et $\mathrm{al}^{5}$ & 1979 & 388 & 12.97 \\
\hline McCullough ${ }^{8}$ & 1980 & 223 & 2.62 \\
\hline Fitzgerald and Connolly9 & 1984 & 82 & 2.43 \\
\hline Mancao et al ${ }^{10}$ & 1998 & 268 & 10.8 \\
\hline Sarguna and Lakshmi ${ }^{11}$ & 2006 & 226 & 3.98 \\
\hline Khan et al ${ }^{12}$ & 2009 & 151 & 1.98 \\
\hline Present study & 2013 & 80 & 0 \\
\hline
\end{tabular}

contrary to various studies, most of the shunt infections are seen in patients with aqueductal stenosis than those having associated myelomeningocele. Of all the steps described in our protocol, prolonged duration of surgery, using intermediate skin incisions and patients who already underwent a shunt poses an increased risk of developing shunt infection in the range of $20 \%, 14.28$, and $14.28 \%$, respectively. The use of preoperative antibiotics and doing shunt as a first case in the operative list significantly reduces the incidence of shunt infection.

The chart comparing the incidence of shunt infection in various studies is shown in - Table 5. Thus, from this study, it is clear that attention to detail and meticulous surgical technique are important if a high rate of shunt infection has to be avoided. This has important implications for the obvious and hidden costs for treating repeated shunt infections in our patients.

\section{Conclusion}

The following conclusions were derived from this study. The shunt infection can be brought to $0 \%$, by observing a simple, practicable protocol (modified from the one suggested by Choux et al $1992^{4}$ ).

In the group, where the protocol was not followed, it is observed that prolonged surgery, use of intermediate skin incision, and previous shunt surgery contribute to increased

Table 4 Chi square test

\begin{tabular}{|l|l|l|l|l|l|}
\hline \multicolumn{2}{|l|}{ Chi-square Tests } & Value & $\mathrm{d} f$ & $\begin{array}{l}\text { Asymp. sig. } \\
\text { (two-sided) }\end{array}$ & $\begin{array}{l}\text { Exact sig. } \\
\text { (two-sided) }\end{array}$ \\
\hline Pearson chi-square & $0.875^{\mathrm{b}}$ & 1 & 0.350 & & $\begin{array}{l}\text { Exact sig. } \\
\text { (one-sided) }\end{array}$ \\
\hline Continuity correction ${ }^{\mathrm{a}}$ & 0.661 & 1 & 0.416 & & \\
\hline Likelihood ratio & 0.875 & 1 & 0.349 & & 0.392 \\
\hline Fisher exact test & & & & & 0.208 \\
\hline Linear-by-linear association & 0.873 & 1 & 0.350 & & \\
\hline No. of valid cases & 486 & & & \\
\hline
\end{tabular}

${ }^{\text {a } C o m p u t e d ~ o n l y ~ f o r ~ a ~} 2 \times 2$ table.

bero cells $(0.0 \%)$ have expected count less than 5 . The minimum expected count is 39.18 . 
risk of shunt infection (ranging from 14 to 20\%). Immersion of shunt tube in saline before its insertion, nonusage of perioperative antibiotics also contributed to increased risk of shunt infection, though to a lesser degree.

\section{Source of Support}

Nil.

\section{Presentation at a Meeting}

No.

\section{Conflicts of Interest}

None.

\section{References}

1 Nulsen FE, Spitz EB. Treatment of hydrocephalus by direct shunt from ventricle to jugular vein. Surg Forum 1952;2:399-403

2 Cushing H. The Cerebral Envelopes. Philadelphia, PA: WB Saunders; 1908

3 Scarff JE. Treatment of hydrocephalus: an historical and critical review of methods and results. J Neurol Neurosurg Psychiatry 1963;26:1-26
4 Choux M, Genitori L, Lang D, Lena G. Shunt implantation: reducing the incidence of shunt infection. J Neurosurg 1992; 77(6):875-880

5 George R, Leibrock L, Epstein M. Long-term analysis of cerebrospinal fluid shunt infections. A 25-year experience. J Neurosurg 1979;51(6):804-811

6 Meirovitch J, Kitai-Cohen Y, Keren G, Fiendler G, Rubinstein E. Cerebrospinal fluid shunt infections in children. Pediatr Infect Dis J 1987;6(10):921-924

7 Haines SJ, Taylor F. Prophylactic methicillin for shunt operations: effects on incidence of shunt malfunction and infection. Childs Brain 1982;9(1):10-22

8 McCullough DC. Symptomatic progressive ventriculomegaly in hydrocephalics with patent shunts and antisiphon devices. Neurosurgery 1986;19(4):617-621

9 Fitzgerald R, Connolly B. An operative technique to reduce valve colonisation. Z Kinderchir 1984;39(Suppl 2):107-108

10 Mancao M, Miller C, Cochrane B, Hoff C, Sauter K, Weber E. Cerebrospinal fluid shunt infections in infants and children in Mobile, Alabama. Acta Paediatr 1998;87(6):667-670

11 Sarguna P, Lakshmi V. Ventriculoperitoneal shunt infections. Indian J Med Microbiol 2006;24(1):52-54

12 Khan I, Burhan M, Nadeem M. A reappraisal of contributing factors leading to shunt infection. J Ayub Med Coll Abbottabad 2009;21(1):66-68 